\title{
Enhancement of wear resistance of mulcher teeth with the help of electrochemical coats
}

\author{
N. M. Belous ${ }^{1}, Y$ u. E. Kisel ${ }^{1, *}$, G. V. Guryanov ${ }^{1}$, and L. M. Markaryants ${ }^{2}$ \\ ${ }^{1}$ Department of Energy Systems, Bryansk State Agrarian University, Bryansk, Russian Federation \\ ${ }^{2}$ Department of Foreign Languages, Moscow State Linguistic Universit, Moscow, Russian Federation
}

\begin{abstract}
Influence of alloying additives in electrolyte and conditions of electrolysis on microhardness, adhesive strength and wear resistance of iron and cobalt coats have been investigated. Conditions of creating coats which make it possible to considerably enhance wear resistance of the mulcher teeth under the conditions of abrasive wear have been established. The process of creating wear resistant coats have been approved and recommended to introduction after the service life of the mulcher teeth sets have been extended.
\end{abstract}

\section{Introduction}

Application of electrochemical iron base alloys [1-4] is a promising method of the machinery parts reconditioning and enhancing their wear resistance. The experience of their utilization shows the advantages of their service properties compared to the coats made of the «pure» electrolytic iron. Introduction of the cobalt irons into the electrolytic iron increases microhardness, strength and wear resistance. At the same time the serviceability of the iron and cobalt coats under the conditions of abrasive wear practically has not been studied. Thus to develop the process of extending the service life of the tillage machinery parts, which wear very quickly, it is necessary to determine the conditions of creating the most wear resistant alloys and study their serviceability in the conditions which have to be almost real. Therefore the aim of this research work was to investigate how composition and conditions of creating the electrochemical coats on the basis of the iron and cobalt-base alloy influence their serviceability under the conditions of abrasive wear.

\section{Research methodology}

Influence of alloying addititives and electrolysis variables on properties and abrasive wear resistance of coats was investigated with the help of the central rotatable uniform planning of the second order at $\mathrm{k}=3[5,6]$. The solution $\mathrm{FeCl}_{2} * 4 \mathrm{H}_{2} \mathrm{O}-500 \mathrm{~g} / \mathrm{l}$ was used as a base electrolyte of iron plating. The iron and cobalt deposits were obtained from the electrolyte whose composition was $\mathrm{FeCl}_{2} * 4 \mathrm{H}_{2} \mathrm{O}-500 \mathrm{~kg} / \mathrm{m}^{3} ; \quad \mathrm{CoSO}_{4} * 7 \mathrm{H}_{2} \mathrm{O}-100 \mathrm{~kg} / \mathrm{m}^{3}$; $\mathrm{Al}_{2}\left(\mathrm{SO}_{4}\right)_{3} * 18 \mathrm{H}_{2} \mathrm{O}-80 \mathrm{~kg} / \mathrm{m}^{3}$. The anionic composition was kept constant due to application of the cobalt and aluminium salts with anions $\mathrm{SO}_{4}{ }^{2-}$ and $\mathrm{Cl}$. Variation intervals of the

\footnotetext{
* Corresponding author: ypk2@mail.ru
} 
electrolyses modes were the electrolyte temperature (T) $30 \ldots 80{ }^{\circ} \mathrm{C}$, current density (Д $)$ from $10 \ldots 50 \mathrm{~A} / \mathrm{dm}^{2}$, the $\mathrm{pH}$ of the solution $-0.2 \ldots 1.2$. The anodic treatment was carried out in electrolyte: $\mathrm{H}_{2} \mathrm{SO}_{4}-300 \ldots 350 \mathrm{~kg} / \mathrm{m}^{3} ; \mathrm{FeCl}_{2} * 4 \mathrm{H}_{2} \mathrm{O}-20 \ldots 22 \mathrm{~kg} / \mathrm{m}^{3}$. The electrochemical coats whose thickness was $0,5 \pm 0,1 \mathrm{~mm}$ were applied to plates made of steel Ct3 (length 30mm, width 30mm, thickness $1 \mathrm{~mm}$ ).

Cohesive strength between the coat and the base $\left(\sigma_{\mathrm{ad}}, \mathrm{MPa}\right)$ was determined with the help of the circular shear method [1]. Microhardness of the coats was determined with the help of the method of microhardness according to GOST 9450- 76. Investigations of the coats wear resistance was carried out in accordance with GOST 23.208- 79. Force of compressing $(\mathrm{P})$ a sample against a rubber roller was changed from $20 \mathrm{H}$ to $88 \mathrm{H}$, the roller revolutions were - $60 \ldots 325$ revolutions per minute (relative sliding speed (V) was 0,3...0,9 $\mathrm{m} / \mathrm{s}$ ). The time of tests was determined because it was necessary to define the tangible extent of wear ( $\mathrm{J}, \mathrm{mg}$ ), which was determined with the help of the weight method with the error $0.05 \mathrm{mg}$. River sand (size of sand grains was no more than $1 \mathrm{~mm}$ ) was used as abrasive material. The primary standards of comparison were the samples of chilled steel $65 \mathrm{G}$ and normalized steel 35.

\section{Research results and their discussion}

The investigations showed that cohesive strength of the iron and cobalt coats depended on the content of alloying additives ions in electrolyte $\left(\mathrm{Co}^{2+}-\mathrm{X}_{1}, \mathrm{Al}^{3+}-\mathrm{X}_{2}, \mathrm{SO}_{4}{ }^{2-}-\mathrm{X}_{3}\right)$ :

$$
\sigma_{\mathrm{ad}}=428,2+23,6 \mathrm{X}_{1}+13,2 \mathrm{X}_{2}-19,5 \mathrm{X}_{3}+7,3 \mathrm{X}_{1}{ }^{2}-8,6 \mathrm{X}_{2}{ }^{2}-8,5 \mathrm{X}_{3}{ }^{2}+5,2 \mathrm{X}_{1} \mathrm{X}_{2}
$$

The graphic analysis of he equation showed that cohesive strength of the iron and cobalt coats depends on change in the content of the alloying additives ions in electrolytes and changes from $300 \mathrm{MPa}$ to $500 \mathrm{MPa}$. When the content of the cobalt ions in electrolyte increases cohesion of the additives with the base also increases. Influence of the aluminium ions in the conditions of the experiment is negligible. Content of the ions $\mathrm{SO}_{4}{ }^{2-}$ within definite limits influences favourably cohesive strength.

Change in concentration of the alloying elements, additives and adhesive strength as well considerably influence mechanical properties of the coats. Thus after introducing cobaltic sulfate their microhardness increased to 6,8...7,2 GPa. Aluminium sulfate influenced microhardness insignifically.

The area of optimum concentration of the components of the iron and cobalt electrolyte which guarantee adhesive strength of the order of $400 \ldots 450 \mathrm{MPa}$ and microhardness $6,0 \ldots 7,0 \mathrm{GPa}$ is near the zero level of the experiment plan. To create such coats may be recommended the electrolyte of the following composition, $\mathrm{kg} / \mathrm{m}^{3}$ : iron chloride $500 \ldots 550$; cobaltic sulfate $100 \ldots 110$; aluminium sulfate $80 \ldots 100$.

Since wear resistance depends on modes of coat application the authors have investigated dependence of wear of the iron and cobalt coats on current density, temperature and the $\mathrm{pH}$ of electrolyte.

After the regressive analysis of the factor experiments had been carried out the authors obtained the empirical relation which adequately described dependence of the electrolytic alloys wear on the variables of electrolysis. After some insignificant coefficients had been excluded the authors got the following equation (temperature, ${ }^{\circ} \mathrm{C}-\mathrm{X}_{4}$; current density, $\mathrm{A} / \mathrm{дм}^{2}-\mathrm{X}_{5}$; the $\mathrm{pH}$ of the solution $-\mathrm{X}_{6}$ ):

$$
\mathrm{J}_{\mathrm{Fe}-\mathrm{Co}}=8,8+0,95 \mathrm{X}_{4}-0,6 \mathrm{X}_{6}+0,69 \mathrm{X}_{6}{ }^{2}+0,5 \mathrm{X}_{4} \mathrm{X}_{5}+0,94 \mathrm{X}_{4} \mathrm{X}_{6}+0,66 \mathrm{X}_{5} \mathrm{X}_{6}
$$

After the temperature had fallen the coat wear resistance enhanced, the optimum value of the $\mathrm{pH}$ of the solution was in the centre of the experiment plan When the current density increased the wear resistance of the alloys enhanced and reached the maximum at $35 . .40$ 
$\mathrm{A} / \mathrm{dm}^{2}$. So this is the optimum mode of creating the strongly bonded wear resistant iron and cobalt deposits: the $\mathrm{pH}$ of the solution $0,7 \ldots 1,0 ; Д_{\kappa}-35 \ldots 40 \mathrm{~A} / \mathrm{dm}^{2} ; \mathrm{T}-40 \ldots 45{ }^{\circ} \mathrm{C}$. Keeping to the recommended modes makes it possible to create alloys having wear resistance two or three times as large compared to the hardened steel 65G (serial share) and eight or ten times as large compared to the normalized steel 35.

The laboratory research results have been used to develop a standard process in order to increase service life of the tillage machine parts with the help of the iron and cobalt-base alloys. The process passed an evaluation test. We took the mulcher teeth sets as an example (figure 1).

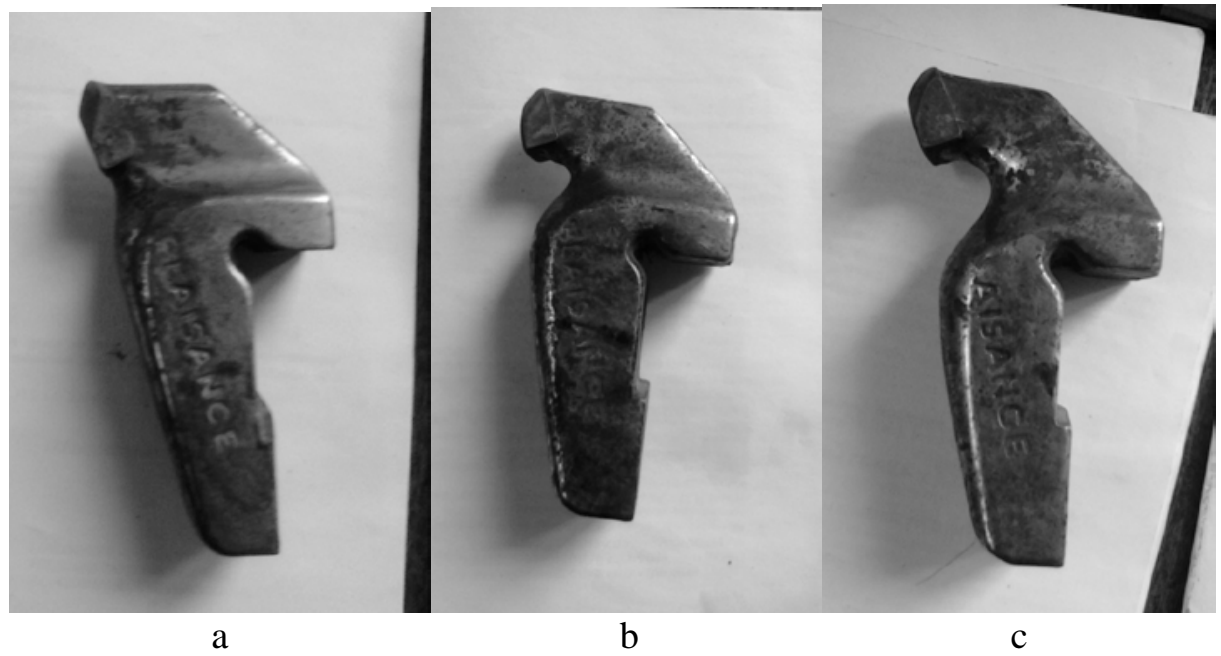

Fig. 1. Wear of a tooth body while in service: a) a new tooth b) 50 per cent wear c) extreme wear.

Analysis of the worn - out teeth showed that while in service the most exposed to wear is their body made of the normalized steel 35 in the attachment zone of the hard-faced tip (alloy T15K6) (figure 1). Thus, service life is limited to a tooth body extreme wear. As soon as a tooth body wears out a hard-faced tip breaks away. To determine a rational method of coats application on the teeth the deposits were applied according to different schemes (figure 2).

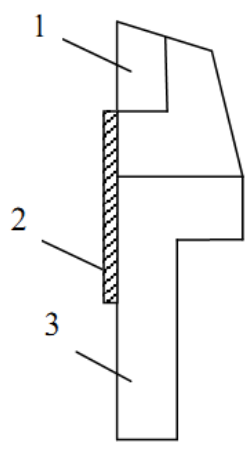

a

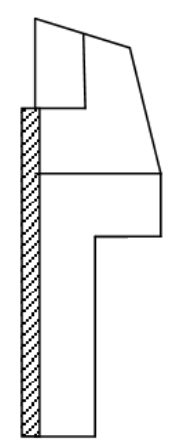

$\mathrm{b}$

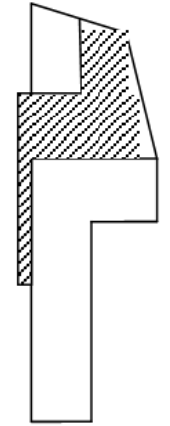

C

1 - hard alloy; 2- a coat; 3- a body

Fig. 2. Schemes of coats application: a) a part of the front tooth surface; b) the front tooth surface; c) the front and side tooth surfaces. 
To evaluate the process a pilot plant has been erected, the shape of protective screens has been corrected, a suspended device to apply the wear resistant coats has been designed (figure 3).

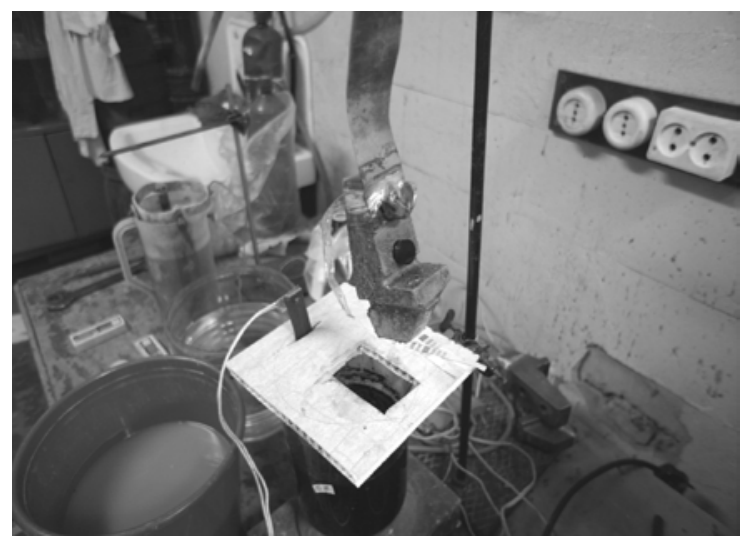

Fig. 3. The pilot plant to apply iron and cobalt alloys on the mulcher teeth.

A batch of teeth (50 teeth) with the iron and cobalt coats whose thickness was $0,4 \ldots 0,5$ $\mathrm{mm}$ (figure 4) has been prepared for field tests.

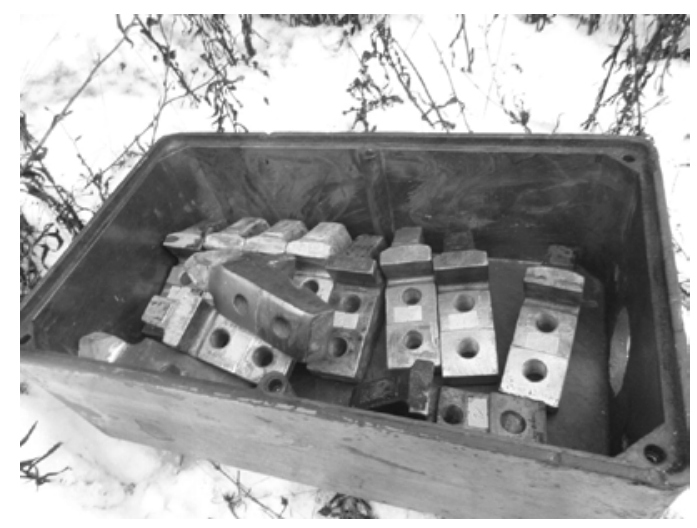

a

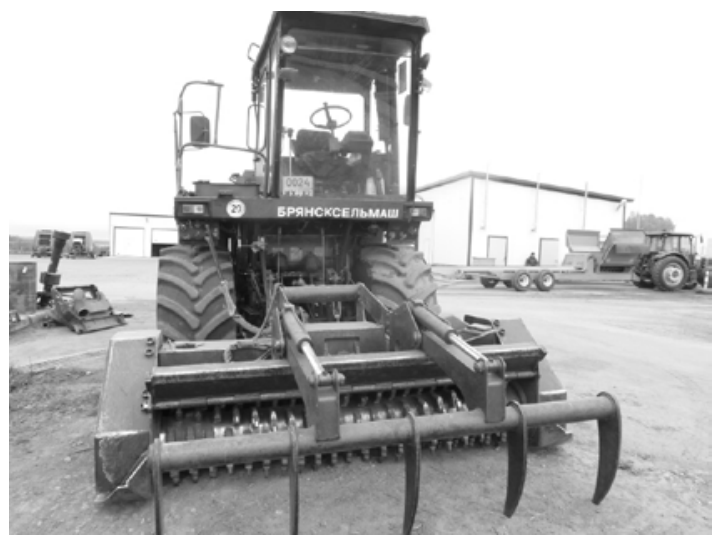

b

Fig. 4. The experimental batch of teeth with coats (a) and a general view of the mulcher set (b). 
The authors carried out the teeth tests using a mulcher manufactured by the Open Joint Stock Company Bryanskselmash on the farms of the Agribusiness Holding Miratorg in Bryansk region (figure 4). The field tests results in the main confirmed the data of the laboratory research.

The developed process of applying electrochemical alloys has a number of technical advantages compared to the existed methods of reconditioning of machinery parts. Easy to access and comparatively cheap materials are used for its implementation. The standard equipment is used for the organization of the plot. In contrast to facing when each part is hardened separately electrochemical alloys are deposited on the batch of parts simultaneously. In the process of electrolysis it is possible to adjust the coats thickness and high uniformity of deposits excludes mechanical working. It is advisable to introduce the technology of increasing service life of the machinery parts under the conditions of abrasive wear at the repair enterprises. It was confirmed by the calculations of economic efficiency which made it possible to determine that the materials and electric power cost will be lowered three or four times compared to the facing of wear resistant alloys.

\section{Conclusions}

Conditions of creating high quality iron and cobalt coats which have high bond strength and whose wear resistance is enhanced two or three times compared to hardened alloyed steels have been established.

After the service life of the mulcher teeth had been extended we can conclude that the process of applying electrolytic iron - base alloys on the parts of farm machinery which wear out very quickly proved high efficiency and advisability of its practical application.

\section{References}

1. Guryanov G V and Kisel Yu E 2015 Wear-resistant Electrochemical Alloys and Composites on Iron Based (Bryansk: BGITA)

2. Kisel J E, Obozov A A and Simokhin S P 2019 Optimal structure of wear-resistant compositional materials IOP Conf. Ser.: Mater. Sci. Eng. 537022032

3. Kisel J E and Guryanov G V 2018 Wear Resistance of Composite Coatings Based on Iron Alloys IOP Conf. Ser.: Mater. Sci. Eng.450 032047

4. Kisel Yu E, Guryanov1 G V, Bezik1 V A, Bezik1 D A, Kaminin V V and Dmitrieva N V 2019 Dependence of strength properties of electrolytic coatings on their substructure. Journal of Physics: Conference Series 1399044071

5. Kolemaev V A Staroverov O V and Turundaevsky V B 1991 Theory of probability and mathematical statistics (Moscow: Higher school Publ.)

6. Yudin M I 2004 Planning an experiment and processing its results (Krasnodar: Krasnodar State Agrarian University) 